\title{
Solar-to-hydrogen peroxide conversion of photocatalytic carbon dots with anthraquinone: Unveiling the dual role of surface functionalities
}

\section{Minsu Gu}

Yonsei University https://orcid.org/0000-0002-6270-7496

Do-Yeon Lee

Yonsei University

Jinhong Mun

Ulsan National Institute of Science and Technology

Dongseok Kim

Yonsei University

\section{Haein Cho}

Yonsei University https://orcid.org/0000-0003-1156-8016

\section{Geunsik Lee}

Ulsan National Institute of Science and Technology https://orcid.org/0000-0002-2477-9990

\section{Byeong-Su Kim}

Yonsei University

Hyoung-il Kim ( $\nabla$ hi.kim@yonsei.ac.kr)

Yonsei University https://orcid.org/0000-0003-4358-1442

\section{Article}

Keywords: hydrogen peroxide, photocatalytic carbon dots, solar-driven photocatalytic production

Posted Date: December 2nd, 2020

DOI: https://doi.org/10.21203/rs.3.rs-109684/v1

License: (1) (1) This work is licensed under a Creative Commons Attribution 4.0 International License.

Read Full License

Version of Record: A version of this preprint was published at Applied Catalysis B: Environmental on April 1st, 2022. See the published version at https://doi.org/10.1016/j.apcatb.2022.121379. 


\section{Abstract}

Solar-driven photocatalytic production of hydrogen peroxide $(\mathrm{H} 2 \mathrm{O} 2)$ requires only sunlight, oxygen, and water, making it a green and sustainable alternative to conventional $\mathrm{H} 2 \mathrm{O} 2$ production processes. We present photocatalytic carbon dots (CDs) as a new candidate for high-performance $\mathrm{H} 2 \mathrm{O} 2$ production. Owing to the generation of an excellent charge carrier and the presence of various oxygen-containing functional groups, CDs showed an outstanding H2O2 production capability of $609.4 \mu \mathrm{mol} g-1 \mathrm{~h}-1$ even in the absence of an electron donor, demonstrating promising self-electron-donating capabilities. Hydroxyl groups on their surface, in particular, serve a dual role as photocatalytic active sites and as electron and proton donors toward the oxygen reduction reaction (ORR). The photocatalytic activity of CDs was significantly improved to $1187.8 \mu \mathrm{mol} g-1$ by functionalizing their surfaces with anthraquinone (AQ) as a co-catalyst; it promoted the charge carrier separation and electrochemically favors the two-electron pathway of ORR. These carbon-based metal-free nanohybrids that are a unique combination of CDs and AQ could offer insights into designing efficient photocatalysts for future solar-to-H2O2 conversion systems.

\section{Introduction}

Hydrogen peroxide $\left(\mathrm{H}_{2} \mathrm{O}_{2}\right)$ is widely used as a clean oxidant in various fields such as organic synthesis, disinfection, and bleaching as it leaves no toxic byproducts and generates only water and oxygen. ${ }^{1}$ As demand for sustainable energy sources grows, $\mathrm{H}_{2} \mathrm{O}_{2}$ has recently received renewed attention as a promising alternative liquid fuel for fuel cell system owing to its higher energy density compared to hydrogen. ${ }^{2}$ The mass production of $\mathrm{H}_{2} \mathrm{O}_{2}$ is currently based on the anthraquinone (AQ) process, which involves the hydrogenation and auto-oxidation reactions between $A Q$ and anthrahydroquinone (AHQ) ${ }^{3}$ However, this method involves costly noble metal catalysts, toxic organic solvents, and hydrogen gas under high pressure and temperature conditions.

In this regard, the photocatalytic production of $\mathrm{H}_{2} \mathrm{O}_{2}$ has emerged as a promising and environmentally friendly alternative to the conventional $A Q$ process because $\mathrm{H}_{2} \mathrm{O}_{2}$ can be produced from both the oxygen reduction reaction (ORR) and water oxidation by harnessing solar energy. ${ }^{4}{ }^{5}$ Considering the high overpotential required for water oxidation to produce $\mathrm{H}_{2} \mathrm{O}_{2}(1.78 \mathrm{~V} v s$. RHE) than that for oxygen evolution reaction (OER) (1.23 V vs. $\mathrm{RHE}$ ), the majority of $\mathrm{H}_{2} \mathrm{O}_{2}$ formation by photocatalysts is derived from the reductive pathway through the ORR. ${ }^{6}$ In general, the ORR is categorized by the number of electrons that participate in the reaction, which depends on the reaction kinetics and energy levels of the active materials. ${ }^{7}$ For the efficient photocatalytic production of $\mathrm{H}_{2} \mathrm{O}_{2}$, high selectivity for the two-electron pathway is thus critical to prevent side reactions that occur through the single-electron pathway and decompose the $\mathrm{H}_{2} \mathrm{O}_{2}$ produced. ${ }^{8}$

Recently, carbon nitride $\left(\mathrm{C}_{3} \mathrm{~N}_{4}\right)$-based photocatalysts have attracted attention for $\mathrm{H}_{2} \mathrm{O}_{2}$ production because of their high selectivity for the two-electron pathway in the ORR. ${ }^{9}$ However, $\mathrm{C}_{3} \mathrm{~N}_{4}$-based 
photocatalysts suffer from limited visible-light absorption due to their large bandgap energy, high rate of charge carrier recombination, and inefficient water oxidation capability. To overcome these intrinsic limitations of $\mathrm{C}_{3} \mathrm{~N}_{4}, \mathrm{C}_{3} \mathrm{~N}_{4}$-based nanocomposites have been developed with various complementary supporters or co-catalysts such as pyromellitic diimide, ${ }^{10}$ polyoxometalates, ${ }^{11}$ black phosphorus, ${ }^{12}$ cobalt phosphide, ${ }^{13}$ carbon nanotube, ${ }^{14}$ reduced graphene oxide, ${ }^{15}$ and $A Q .{ }^{16}$

As an alternative to semiconducting quantum dots, carbon dots (CDs) possess interesting physical, optical, and chemical properties for various energy- and bio-applications ${ }^{17-20}$ due to their aqueous solubility, abundant functional groups, excellent light absorption, and carrier generation. In this study, we report the design and a synthesis of new class of $\mathrm{CDs}$ as high-performance $\mathrm{H}_{2} \mathrm{O}_{2}$ photocatalysts (Fig. 1). The unique photoelectron donating capability of CDs with oxygen-bearing functionalities (e.g., hydroxyl, hydroquinone, and carboxyl moieties) allows them to present the outstanding photocatalytic performance toward $\mathrm{H}_{2} \mathrm{O}_{2}$ evolution, outperforming most of $\mathrm{C}_{3} \mathrm{~N}_{4}$ - and semiconducting nanoparticlebased photocatalysts in the absence of electron donors (i.e., alcohols). More importantly, by taking advantage of the unique surface chemistry of $C D$ s, we functionalize their surfaces with $A Q$ molecules (CD-AQ) to further enhance their photocatalytic performance. As a co-catalytic supporter, AQ serves to promote the two-electron reaction for $\mathrm{H}_{2} \mathrm{O}_{2}$ production. We envision that this unique combination of $\mathrm{CD}$ coupled with $A Q$ will provide new insights into the design of metal-free carbon-based photocatalytic nanohybrids.

\section{Results}

Synthesis of CD and CD-AQ. CDs were initially prepared via a hydrothermal reaction using citric acid (CA) as a carbon source in the presence of ethylene diamine (EDA). EDA acts as both a nitrogen source and a surface-passivating agent in this reaction (Fig. 1a). The as-synthesized CDs showed high aqueous stability with a $\zeta$-potential of $+5.2 \mathrm{mV}$ at $\mathrm{pH} 7$ owing to the presence of functional amine groups on the CD surface derived from EDA. In order to introduce AQ molecules as a co-catalyst, we employed $N$-ethyl$\mathrm{N}$-(3-dimethylaminopropyl)carbodiimide methiodide (EDC) to mediate the surface functionalization of CDs through the reaction between amines and carboxylic acid-containing AQ molecules. Considering the solubility of all reactants, ethanol was used as a suitable solvent for the functionalization.

High-resolution transmission electron microscopy (HR-TEM) analysis revealed the nearly spherical morphology of CD and CD-AQ with an average diameter of $4.5 \pm 0.8 \mathrm{~nm}$ and $9.9 \pm 2.3 \mathrm{~nm}$ (Fig. $1 \mathrm{~b}$ and Fig. $\mathrm{S} 1$ in the Supplementary Information). The bandgap energy $\left(E_{\mathrm{g}}\right)$ and energy levels of the conduction band (CB) and valence band (VB) of CD and CD-AQ were respectively determined by using Tauc's plot from UV/vis spectra and ultraviolet photoelectron spectroscopy (UPS) (Fig. S2 and S3). Interestingly, there was no significant difference in the bandgap energies $(3.2-3.3 \mathrm{eV})$ or in the energy level of $C B$ and VB regardless of the types of CDs used.

Successful functionalization by $A Q$ was also monitored by UV/vis and photoluminescence (PL) spectroscopy (Fig. 1c and 1d). The CDs exhibited characteristic absorption peaks at $237 \mathrm{~nm}\left(\pi-\pi^{*}\right.$ 
transition of $\mathrm{sp}^{2}$-carbon network) and $341 \mathrm{~nm}\left(\mathrm{n}-\pi^{*}\right.$ transition of carbonyl groups), confirming the presence of various surface functional groups. The AQ molecules used for the functionalization displayed distinct absorbance at $258 \mathrm{~nm}$ and $335 \mathrm{~nm}$ owing to the $\pi-\pi^{\star}$ transition of benzoid and quinoid. ${ }^{21}$ The spectra of the CD-AQ displayed the presence of absorption peaks of both $C D$ and $A Q$ molecules, indicating successful surface functionalization. The characteristic PL spectra of both $C D$ and CD-AQ were found to depend on the excitation wavelength (Fig. S4). The maximum emission of CD was observed at $429 \mathrm{~nm}$ upon excitation at $335 \mathrm{~nm}$, while that of CD-AQ was located at $434 \mathrm{~nm}$ upon excitation at $345 \mathrm{~nm}$. In addition to shorter PL lifetime of CD-AQ than CD obtained by time-correlated single photon counting (TCSPC) measurements (Fig. S5), the PL intensity of CD-AQ was decreased by $87 \%$ upon conjugation with $A Q$ on the surface of $C D$ (Fig. 1d), indicating the efficient transfer of the photoexcited charge carriers from $C D$ to $A Q$.

The successful functionalization of CD-AQ was further investigated by Fourier transform infrared (FT-IR) spectroscopy and X-ray photoelectron spectroscopy (XPS) (Fig. 2). In the FT-IR spectra of both CD and AQ molecules, a peak at $1700 \mathrm{~cm}^{-1}$ was observed corresponding to the stretching vibration of $\mathrm{C}=0$ (Fig. 2a). However, the $\mathrm{C}=0$ stretching vibration peak of CD-AQ shifted slightly to $1656 \mathrm{~cm}^{-1}$, indicating the successful amide coupling between $\mathrm{CD}$ and $\mathrm{AQ} .{ }^{22}$ In addition, a new peak attributed to the amide bond was also observed in 3300 to $3480 \mathrm{~cm}^{-1}$ in the XPS spectrum of the CD-AQ. ${ }^{23}$ In the C 1s XPS spectra, the peak intensity of the oxygen-containing groups at a higher binding energy such as $\mathrm{C}-\mathrm{OH}, \mathrm{C}=\mathrm{O}$, and $\mathrm{COOH}$ decreased, while the peaks at 284.2 and $285.6 \mathrm{eV}$ assigned to the $\mathrm{C}=\mathrm{C}$ and $\mathrm{C}-\mathrm{N}$, respectively, increased after functionalization of $A Q$ on $C D$ owing to the formation of an amide bond. However, a simple mixture of $C D$ and $A Q$ (in the absence of the EDC agent) did not indicate the formation of an amide group, suggesting a critical role of EDC in the coupling reaction of CD-AQ (Fig. 2b). In addition, a new characteristic $\mathrm{N}$ 1s peak at $402 \mathrm{eV}$ was observed for the $\mathrm{CD}-\mathrm{AQ}$, which was assigned to the amide bond without noticeable changes in the other $\mathrm{N}$-configurations of graphitic-, pyridinic-, and pyrrolic-N (Fig. 2C). The peak shift of N1s of CD-AQ to a lower energy compared to pristine CD and CD+AQ (mix) is also attributed to the electron delocalization by amide coupling with $\mathrm{AQ}$ molecules, which can also offer a strong evidence for successful functionalization of $A Q$ on CDs. Taken together, the successful chemical functionalization of $A Q$ on $C D$ to afford a CD-AQ was confirmed. Meanwhile, the relative mass ratio of $A Q$ to $\mathrm{CD}$ was determined to be 1.7 in the CD-AQ nanocomposite based on UV/vis spectroscopy (Fig. S6).

Photocatalytic production of $\mathrm{H}_{2} \mathrm{O}_{2}$ with $\mathrm{CDs}$. The molar ratio of the $\mathrm{CD}$ precursors $\mathrm{CA}$ to EDA, for instance, significantly affects the light absorption and photocatalytic properties of CDs. ${ }^{24}$ Thus, before investigating the photocatalytic performance of as-synthesized CD-AQ, we first evaluated the performance of $\mathrm{CDs}$ while varying the molar ratio of their precursors. All CDs were successfully synthesized, showing a characteristic $n-\pi^{\star}$ transition peak of carbonyl groups at $341 \mathrm{~nm}$ (Fig. S7). Under solar-simulated light illumination, $\mathrm{H}_{2} \mathrm{O}_{2}$ was produced with an initial production rate of 148 (CA:EDA ratio of 5:2), 423 (5:5), and $89 \mu \mathrm{mol} \mathrm{g}^{-1} \mathrm{~h}^{-1}$ (5:7) for CDs prepared with a different molar ratio of CA to EDA, respectively (Fig. 3a). Interestingly, the highest photocatalytic performance was observed for CD with an equimolar ratio of CA to EDA (Fig. S8). This can be accounted for by considering the high degree of 
carbonization with a higher fraction of $\mathrm{C}=\mathrm{C}$ bond in reference to $\mathrm{C}-\mathrm{N}$ in $\mathrm{C} 1 \mathrm{~s}$ XPS spectra than those of CDs prepared from other precursor ratios (Fig. S9), resulting in enhanced light absorption under a wide range of wavelengths. Hereafter, $C D$ prepared at a ratio of 5:5 was selected for further experiments owing to its high photocatalytic $\mathrm{H}_{2} \mathrm{O}_{2}$ production.

In the absence of light irradiation and $\mathrm{O}_{2}$ source, $\mathrm{CD}$ showed a negligible photocatalytic performance for $\mathrm{H}_{2} \mathrm{O}_{2}$ generation, indicating that the reaction required to produce $\mathrm{H}_{2} \mathrm{O}_{2}$ is a photoresponsive catalytic reaction through the ORR and consumes $\mathrm{O}_{2}$ (Fig. $3 \mathrm{~b}$ and Fig. S10). We also conducted the photocatalytic $\mathrm{H}_{2} \mathrm{O}_{2}$ production on $\mathrm{CD}$ in the presence of $1 \mathrm{mM}$ of CA and EDA to evaluate the effect of the residual precursors in as-prepared $C D$ s because these precursors are also known to serve as electron donors in conventional $\mathrm{H}_{2} \mathrm{O}_{2}$ production processes. ${ }^{25}$ However, the amount of $\mathrm{H}_{2} \mathrm{O}_{2}$ generated over $2 \mathrm{~h}$ decreased notably in the presence of each and both precursors (i.e., $\mathrm{CA}$ and $\mathrm{EDA}$ ), with corresponding performances of $699.8 \mu \mathrm{mol} \mathrm{g}^{-1}$ (CA only), $711.2 \mu \mathrm{mol} \mathrm{g}^{-1}$ (EDA only), and $177.8 \mu \mathrm{mol} \mathrm{g}^{-1}$ (both CA and EDA), respectively, compared to $845 \mu \mathrm{mol} \mathrm{g}{ }^{-1}$ for the bare CDs. The results indicate that the presence of residual $C A$ and EDA interferes with the photocatalytic performance of CD instead of accelerating $\mathrm{H}_{2} \mathrm{O}_{2}$ production by acting as electron donors. It is inferred that CA and EDA are adsorbed on CDs by interacting with functional groups may interrupt surface reactions (e.g., substrate adsorption, electron transfer from donors and to acceptors) by covering the active reaction sites on the surfaces of the CDs.

Most semiconductor photocatalysts cannot achieve the $\mathrm{H}_{2} \mathrm{O}_{2}$ production and water oxidation simultaneously in the absence of sacrificial electron donors due to insufficient oxidation power and inefficient charge carrier separation. ${ }^{26}$ Thus, much effort has been made towards developing photocatalysts that enable the efficient $\mathrm{H}_{2} \mathrm{O}_{2}$ production only from water and molecular oxygen by tuning their structural, chemical, and electrical properties. ${ }^{27-30}$ As one of the most efficient photocatalysts for $\mathrm{H}_{2} \mathrm{O}_{2}$ production owing to its unique chemical process through the formation of a superoxo radical and 1,4-endoperoxide species, ${ }^{9,}{ }^{10} \mathrm{C}_{3} \mathrm{~N}_{4}$ generated $\mathrm{H}_{2} \mathrm{O}_{2}$ at a rate of $606.7 \mu \mathrm{mol} \mathrm{g} \mathrm{g}^{-1} \mathrm{~h}^{-1}$. However, the CD prepared in this study demonstrated an even higher $\mathrm{H}_{2} \mathrm{O}_{2}$ product rate of $631.8 \mu \mathrm{mol} \mathrm{g}^{-1} \mathrm{~h}^{-1}$ in the presence of ethanol as a sacrificial electron donor. Most interestingly, there was negligible production of $\mathrm{H}_{2} \mathrm{O}_{2}$ in $\mathrm{C}_{3} \mathrm{~N}_{4}\left(69.6 \mu \mathrm{mol} \mathrm{g}^{-1} \mathrm{~h}^{-1}\right)$, in the absence of ethanol electron donor, while CD could efficiently produce $\mathrm{H}_{2} \mathrm{O}_{2}\left(609.4 \mu \mathrm{mol} \mathrm{g}-1 \mathrm{~h}^{-1}\right)$ in the same conditions (Fig. 3c). The significant decrease in $\mathrm{H}_{2} \mathrm{O}_{2}$ production on $\mathrm{CD}$ in the presence of both $\mathrm{CA}$ and EDA supports the finding that these potential impurities merely act as retardants for $\mathrm{H}_{2} \mathrm{O}_{2}$ production, rather than as electron donors (Fig. 3d).

Photocatalytic production of $\mathrm{H}_{2} \mathrm{O}_{2}$ with $\mathrm{CD}-\mathrm{AQ}$. We further functionalized $\mathrm{CD}$ s with $\mathrm{AQ}$ molecules, which improved the photocatalytic effect of hybrid CD-AQ. In addition, we optimized the photocatalytic performance of $C D-A Q$ via varying degrees of surface functionalization of $A Q$ molecules on the surfaces of the former (Fig. S11). Surprisingly, the kinetics of $\mathrm{H}_{2} \mathrm{O}_{2}$ production improved significantly for highly functionalized CD-AQ $\left(1187.8 \mu \mathrm{mol} \mathrm{g}^{-1}\right)$ compared to bare CD $\left(845.4 \mu \mathrm{mol} \mathrm{g}^{-1}\right)$ under solar-simulated light 
illumination for $2 \mathrm{~h}$ (Fig. 4a). Although $\mathrm{AQ}$ itself can produce $\mathrm{H}_{2} \mathrm{O}_{2}$ under UV illumination via an irreversible photochemical reaction, ${ }^{31}$ the photochemical production of $\mathrm{H}_{2} \mathrm{O}_{2}$ using bare $A Q$ was merely $237.2 \mu \mathrm{mol} \mathrm{g}{ }^{-1}$ even at a much higher concentration of $0.5 \mathrm{~g} \mathrm{~L}^{-1}$. This enhanced performance by functionalization with $A Q$ agrees with our previous finding that the $A Q$ accelerated the photocatalytic $\mathrm{H}_{2} \mathrm{O}_{2}$ production of $\mathrm{C}_{3} \mathrm{~N}_{4}$ by acting as a co-catalyst. ${ }^{16}$ The combination of $C D$ and $A Q$ in the CD-AQ hybrid is unique and beneficial for efficient dual-photocatalytic process for $\mathrm{H}_{2} \mathrm{O}_{2}$ production, not only because it introduces other catalytic active sites, but also because it promotes efficient charge carrier separation, as demonstrated by the decreased PL intensity and lifetime of CD-AQ (Fig. 1d and Fig. S5) as well as the enhanced apparent quantum yield (AQY) of CDs upon functionalization with $A Q$; the AQY profile of CD$A Q$ analogously resembles its absorption spectrum and is more pronounced than that of $C D$ regardless of the excitation wavelengths (Fig. S12).

The $\mathrm{pH}$-dependent photocatalytic effect of $\mathrm{CD}-\mathrm{AQ}$ for $\mathrm{H}_{2} \mathrm{O}_{2}$ production was investigated because the photocatalytic ORR is governed by the proton-coupled electron transfer (PCET) reaction as in the following reaction (1):

$$
\mathrm{O}_{2}+2 \mathrm{H}^{+}+2 \mathrm{e}^{-} \rightarrow \mathrm{H}_{2} \mathrm{O}_{2}
$$

where the photoexcited electrons from the photocatalyst react with molecular oxygen and protons in the solution. As decreasing $\mathrm{pH}$, therefore, $\mathrm{H}_{2} \mathrm{O}_{2}$ production rate of $\mathrm{CD}-\mathrm{AQ}$ increased considerably, to 2512 $\mu \mathrm{mol} \mathrm{g} \mathrm{g}^{-1} \mathrm{~h}^{-1}$ at $\mathrm{pH} 1$, which was an approximately 4 -fold increase compared to $\mathrm{pH} 6$ (Fig. $4 \mathrm{~b}$ and Fig. S13), outperforming other carbon-based photocatalysts for $\mathrm{H}_{2} \mathrm{O}_{2}$ production reported to date (Tables S1). This tendency clearly supports the fact that the formation of $\mathrm{H}_{2} \mathrm{O}_{2}$ on CD-AQ is based mainly on the photocatalytic ORR under solar-simulated light illuminations. Similar trends have been observed with other photocatalytic systems used for photocatalytic $\mathrm{H}_{2} \mathrm{O}_{2}$ production. ${ }^{32}$

Long-term stability is another critical requirement in the development of efficient photocatalysts. We therefore performed a long-term performance and stability tests of CD-AQ. There was a continuous increase in $\mathrm{H}_{2} \mathrm{O}_{2}$ concentration for a $12 \mathrm{~h}$ reaction by CD-AQ up to $4,700 \mu \mathrm{mol} \mathrm{g}{ }^{-1}$ at pH 6 and 28,600 $\mu \mathrm{mol} \mathrm{g} \mathrm{g}^{-1}$ at $\mathrm{pH} 3$, respectively (Fig. S14). The slight decrease in the $\mathrm{H}_{2} \mathrm{O}_{2}$ production rate was probably due to the increase of $\mathrm{pH}$ (e.g., from $\mathrm{pH} 6$ to $\mathrm{pH}$ 7.26) due to the protons consumed during the photocatalytic formation of $\mathrm{H}_{2} \mathrm{O}_{2}$ through the PCET reaction, and in situ photodecomposition of produced $\mathrm{H}_{2} \mathrm{O}_{2}$ by the absorption of UV light. ${ }^{33}$ The decomposition of $\mathrm{H}_{2} \mathrm{O}_{2}$ by CD and CD-AQ was further examined because in situ produced $\mathrm{H}_{2} \mathrm{O}_{2}$ can be decomposed by both electrons from $\mathrm{CB}$ and holes from $V B$, which are generated during photocatalytic process. Unlike the gradual decrease of initial $\mathrm{H}_{2} \mathrm{O}_{2}$ concentration obtained with $\mathrm{C}_{3} \mathrm{~N}_{4}$ for $2 \mathrm{~h}$ of reaction, a negligible decomposition (less than $1 \%$ ) of $\mathrm{H}_{2} \mathrm{O}_{2}$ was observed with CD and CD-AQ (Fig. S15). Furthermore, there was no change in the specific absorbance of $\mathrm{CD}$ after the $2 \mathrm{~h}$ photocatalytic process. Collectively, these results indicate that the $\mathrm{CD}$ - 
based photocatalysts are an ideal candidate for the photocatalytic generation of $\mathrm{H}_{2} \mathrm{O}_{2}$ owing to their outstanding performance for $\mathrm{H}_{2} \mathrm{O}_{2}$ evolution in electron donor-free systems as well as their superior photochemical stability with a limited sluggish decomposition of $\mathrm{H}_{2} \mathrm{O}_{2}$.

Electrochemical properties of CD and CD-AQ. Electrochemical analysis was conducted to verify the role of $\mathrm{AQ}$ molecules in enhancing the catalytic performance of CD-AQ nanocomposites. AQ exhibits distinct oxidation and reduction peaks and an extremely fast two-electron redox reaction with a redox potential that shifts depending on the functional groups on the AQ. ${ }^{34}$ Therefore, we investigated the cyclic voltammetry (CV) of $\mathrm{CD}$ and $\mathrm{CD}-\mathrm{AQ}$ in the potential range from -1.2 to $0.0 \mathrm{~V} \mathrm{vs}$. Ag/ $\mathrm{AgCl}$ (Fig. S16). The CV curve of CD-AQ showed an anodic peak at $-0.52 \mathrm{~V}$ and a cathodic peak at $-0.60 \mathrm{~V}$, corresponding to the redox peaks of $A Q$, whereas that of $C D$ showed a rectangle shape associated with a non-Faradaic current (without distinct peaks). These results imply that $A Q$ was successfully functionalized on the $C D s$, thus CD-AQ showed the higher current density than that of $C D$ for ORR in $\mathrm{O}_{2}$-saturated condition. As a result, the electrochemical kinetics of electrons transferred within CD-AQ nanocomposites can be affected by the functionalized $A Q$.

To evaluate the electrochemical kinetics of $C D$ and $C D-A Q$ toward the ORR, we used a rotating ring disk electrode (RRDE) to examine linear sweep voltammetry (LSV) (Fig. 5). The CD-AQ exhibited a ring and disk current density that was more than twice the current density of the CD (Fig. 5a and 5b). The average electron transfer number of $\mathrm{CD}$ was calculated as 2.4 and the average efficiency of $\mathrm{H}_{2} \mathrm{O}_{2}$ production was $78.4 \%$ in the potential ranges from -0.80 to $-0.40 \mathrm{~V}(v s . \mathrm{Ag} / \mathrm{AgCl})$, suggesting that $\mathrm{CD}$ is responsible for the two-electron ORR pathway (Fig. 5c). The two reduction plateaus observed in LSV curve can be a key evidence for electrochemical $\mathrm{H}_{2} \mathrm{O}_{2}$ production. The electrochemical ORR performance of $\mathrm{CD}$ is known to be governed through consecutive two-electron steps upon generation of $\mathrm{H}_{2} \mathrm{O}_{2}$ as an intermediate by slow kinetics on carbon surfaces containing chemical functional groups. ${ }^{35}$ In addition, the imbalance in charge density also increases the oxygen adsorption on the surface of $C D$, thereby increasing oxygen solubility. It also participates in the release of $\mathrm{H}_{2} \mathrm{O}_{2}$ as an intermediate. Interestingly, CD-AQ showed not only highly enhanced electrochemical kinetics with a lower charge transfer resistance $\left(R_{\mathrm{ct}}\right)$ measured by electrochemical impedance spectroscopy (EIS) (Fig. S17 and Table S2), but also increased selectivity compared to $C D$ alone, with an average electron transfer number of 2.3 and an average $\mathrm{H}_{2} \mathrm{O}_{2}$ selectivity of $80.6 \%$ as the rotating speed in the same potential (Fig. $5 \mathrm{~d}$ ). These results indicate that the chemical functionalization of $A Q$ onto $C D$ creates a more efficient catalyst for generating $\mathrm{H}_{2} \mathrm{O}_{2}$ by enhancing the facile charge transfer and facilitating the selective two-electron pathway of the ORR.

Mechanism of the CD-AQ. The structural advantages of versatile CD-based catalysts (containing a unique $\mathrm{sp}^{2} / \mathrm{sp}^{3}$ hybrid carbon structure with various oxygen- and nitrogen-functional groups) facilitate and promote various chemical reactions, which suggests their widespread utility in a number of applications. ${ }^{19,36-39}$ In this regard, we monitored the time profile of specific chemical compositions of CD during the photocatalytic process to clarify the underlying mechanisms behind the outstanding performance of CD-AQ in the evolution of $\mathrm{H}_{2} \mathrm{O}_{2}$ (Fig. 6b and Fig. S18). 
The deconvoluted high-resolution $\mathrm{C}$ 1s spectra collected from XPS clearly revealed that the oxidative conversion of surface functional groups of $\mathrm{CD}$ took place during photocatalytic $\mathrm{H}_{2} \mathrm{O}_{2}$ production in which the $\mathrm{C}-\mathrm{OH}$ group was diminished considerably whereas the $\mathrm{C}=0$ group was increased at the same time. This result agrees with our previous finding that the specific transformation of surface functional groups on $\mathrm{CD}$, from hydroquinone to benzoquinone, was involved in and promoted the formation of metal nanoparticles onto the surface of $C D$ by reducing metal ions under UV illumination. ${ }^{20,40}$ Moreover, hydroxyl and hydroquinone groups are known to be very effective for the formation of $\mathrm{H}_{2} \mathrm{O}_{2}$ through ORR in the presence of molecular oxygen. ${ }^{16}$

In order to further elucidate the proposed mechanism and active sites on the surface of CDs, we conducted density-functional theory (DFT) calculation to investigate the adsorption energy and free energy of carbon surface like graphene nanoribbon as a model of $C D$ and $A Q$-anchored carbon surfaces. In general, the two-electron ORR pathway follows two-step reactions for adsorption and desorption of oxygen with the formation of intermediate ${ }^{*} \mathrm{OOH}$ as in step 1 and 2 :

$\mathrm{O}_{2}+\mathrm{H}_{2} \mathrm{O}+\mathrm{e}^{-}+*$ à $* \mathrm{OOH}+\mathrm{OH}^{-}($step 1$)$

${ }^{*} \mathrm{OOH}+\mathrm{e}^{-} \mathrm{à} \mathrm{HO}_{2}{ }^{-}+*($ step 2$)$

where * is an active site and ${ }^{*} \mathrm{OOH}$ is a key intermediate that plays a pivotal role in overall two-electron ORR performance. As a result, the adsorption energy of ${ }^{*} \mathrm{OOH}\left(\Delta \mathrm{G}_{* \mathrm{OOH}}\right)$ can be a descriptor with corresponding the thermodynamic limiting potential $\left(U_{L}\right)$ for determining the active sites. An ideal catalyst for $\mathrm{H}_{2} \mathrm{O}_{2}$ production has a $\Delta \mathrm{G}{ }_{\mathrm{OOOH}}$ of $4.22 \mathrm{eV}$, which provides the highest activity with the thermodynamic equilibrium potential $\left(U^{0}=0.70 \mathrm{~V}\right)$ in the activity volcano plot. Thus, we calculated the energy barrier in terms of free energy (Fig. 6c and S19) and adsorption energy (Fig. 6d) of CD and CD-AQ. The corresponding atomic structures of the examined $C D$ and $C D-A Q$ are shown in Fig. 6e. The ORR on AQ showed a thermodynamically uphill reaction by high free energy of $0.728 \mathrm{eV}$, resulting in low adsorption of $\mathrm{OOH}$ on $\mathrm{AQ}$ anchored carbon matrix. Although $\mathrm{AQ}$ method is commonly used in industrial $\mathrm{H}_{2} \mathrm{O}_{2}$ production, it is because $A Q$ mechanism is not a competitive pathway for carbon-based catalysts and $A Q$ follows different catalytic mechanism reported in other studies using various quinone-enriched molecules with similar DFT results of $A Q$ molecules. ${ }^{41}$ On the other hand, the oxidized CD surface (herein a form of CD-ketone for DFT calculation) exhibited the highest activity compared to bare CD and other carbon matrix, which suggests a plenty of oxygen functional groups on the surface of CD can serve as thermodynamically active sites in accord with experimental XPS results.

From these results, we propose the possible mechanisms that retain a number of elementary reaction steps occurring on the surface of both $\mathrm{CD}$ and CD-AQ systems to form $\mathrm{H}_{2} \mathrm{O}_{2}$ (Fig. 6a). Specifically, $\mathrm{CD}$ initially generates the photoexcited electrons and holes owing to its appropriate bandgap energy. The photoexcited electrons are then transferred to the active sites (hydroxyl groups) on the surface of CDs, resulting in the reduction of $\mathrm{O}_{2}$ that produces $\mathrm{H}_{2} \mathrm{O}_{2}$ with the surrounding protons. This step is followed by 
the conversion of the hydroxyl groups to carbonyl groups on the surface of CDs. These protons can not only be supplied by the dissociation of nearby carboxylic acid groups; they can also be generated by hydroxyl groups from the CDs themselves in the absence of electron- and proton donors such as ethanol (Fig. S20). This interpretation is also based on the poor performance of $\mathrm{C}_{3} \mathrm{~N}_{4}$ in the absence of ethanol due to the lack of surface functional groups (Fig. 3c).

Considering the results from the reduced $\mathrm{PL}$ and electrochemical analysis, the role of $\mathrm{AQ}$ in $\mathrm{CD}-\mathrm{AQ}$ for $\mathrm{H}_{2} \mathrm{O}_{2}$ production was proven to be that of a co-catalyst that promotes charge carrier separation and selectivity for $\mathrm{H}_{2} \mathrm{O}_{2}$ formation through the sequential hydrogenation- dehydrogenation of $A Q$. In CD-AQ, photoexcited electrons are transferred efficiently from CD to AQ molecules. $\mathrm{O}_{2}$ is then reduced by a reversible reaction between $A Q$ and $A H Q$ with electrons and protons donated from the $C D$ s or ethanol.

\section{Discussion}

We developed highly efficient CD-based metal-free photocatalysts towards the environmentally friendly production of $\mathrm{H}_{2} \mathrm{O}_{2}$. The $\mathrm{CDs}$ and $\mathrm{CD}-\mathrm{AQ}$ nanocomposites exhibited a superior photocatalytic performance, and physical and chemical stability compared to $\mathrm{C}_{3} \mathrm{~N}_{4}$-based photocatalysts as, with $\mathrm{H}_{2} \mathrm{O}_{2}$ production gradually increasing during the long-term light irradiation over $12 \mathrm{~h}$. The AQ molecules were successfully functionalized on the surface of $\mathrm{CDs}$, where they act as co-catalysts that promote efficient charge carrier separation from the photoexcited $\mathrm{CDs}$ and accelerate the two-electron ORR pathway. This results in significantly enhanced electron transfer kinetics for $\mathrm{H}_{2} \mathrm{O}_{2}$ production. The photocatalytic mechanism was elucidated by examining the change in the chemical compositions of the surface functional groups of CDs; a reversible reaction occurred between the hydroxyl and carbonyl groups during photocatalytic production of $\mathrm{H}_{2} \mathrm{O}_{2}$ under light illumination. Notably, CDs showed a considerable $\mathrm{H}_{2} \mathrm{O}_{2}$ production rate without the addition of any extra electron donors owing to their unique self-electron donating capabilities. We anticipate that this new photosystem, which boosts photocatalytic effects by combining two or more components, can be extended further to design other multi-functional hybrid photocatalysts that facilitate selective electron transfer and wide visible light absorption as a step towards highly efficient solar-to-fuel conversion systems.

\section{Methods}

\section{Materials}

Citric acid (CA), ethylenediamine (99\%, EDA), anthraquinone-2-carboxylic acid (AQ), $N, N$ Diethyl-1.4-phenylenediamine sulfate (DPD), peroxidase, from horseradish (POD, type VIA), and $N$-ethyl- $N$-(3-dimethylaminopropyl)carbodiimide methiodide (EDC) were purchased from Sigma-Aldrich and used without further purification. 
The synthesis of the CDs involves a hydrothermal reaction of a mixture of CA and EDA in deionized (DI) water. Specifically, $960 \mathrm{mg}$ of CA (5.0 mmol) and $347 \mu \mathrm{L}$ of EDA (5.0 mmol) were dissolved in $10 \mathrm{~mL}$ of DI water. For comparison with 5:2 and 5:7 CDs, $2.0 \mathrm{mmol}$ and $7.0 \mathrm{mmol}$ of EDA were used, respectively. The solution was placed into a muffle furnace (MF-22G, JEIO TECH) and heated at $180^{\circ} \mathrm{C}$ for $6 \mathrm{~h}$. Thereafter, the obtained brownish suspension was dialyzed (SpectraPore MWCO 500-1,000) in DI water over 2 weeks to remove salts, unreacted chemicals, and much smaller CDs. Note that a thorough dialysis process is critical to overall performance for $\mathrm{H}_{2} \mathrm{O}_{2}$ production of CDs as shown in Fig 3 . After dialysis process, the aqueous CD solution was evaporated by a rotary evaporator and the resulting CD powder was re-dispersed by DI water at a desired concentration (10 mg $\left.\mathrm{mL}^{-1}\right)$.

\section{Synthesis of functionalized CDs with anthraquinone (CD-AQ)}

A suspension of $4 \mathrm{~mL}$ of the as-prepared CDs (conc. $10 \mathrm{mg} \mathrm{mL}^{-1}$ ) was reacted with the excess amount of $100 \mathrm{~mL}$ of AQ solution dissolved in ethanol (2 mM) for $12 \mathrm{~h}$ in the presence of $500 \mathrm{mg}$ of EDC. The resulting suspension was dialyzed (SpectraPore MWCO 500 - 1,000) in ethanol over 2 weeks to remove unreacted EDC and AQ.

\section{Characterization}

A UV/vis spectrophotometer (UV-2550, Shimadzu) was used to measure the absorbance. The photoluminescence (PL) emission was determined with a Varian Cary 5000 spectrophotometer. Ultraviolet Photoelectron Spectroscopy (UPS) (AXIS-NOVA, Kratos Inc.) was used to measure the energy level. The chemical structure was analyzed by X-ray photoelectron spectroscopy (XPS) (K-alpha, Thermo Fisher) and Fourier-transform infrared spectroscopy (FT-IR) (Varian, Cray 660). The morphology and size of the CDs and CD-AQ were measured using Transmission electron microscopy (TEM) (JEOL, JEM-F200).

\section{Photocatalytic $\mathrm{H}_{2} \mathrm{O}_{2}$ production}

Photocatalytic $\mathrm{H}_{2} \mathrm{O}_{2}$ production experiments were carried out by irradiating simulated solar light (AM 1.5, $100 \mathrm{~mW} \mathrm{~cm}^{-2}$ ) from a 150-W Xenon Arc lamp to the aqueous suspension of various CDs in the presence or absence of $10 \mathrm{vol} \%$ ethanol as an electron donor. The 
suspension was continuously purged with $\mathrm{O}_{2}$ for 15 min before and during illumination. The incident light intensity was determined using a Newport calibrated Si solar cell. Briefly, a sample aliquot was collected from the reaction suspension using a syringe. A DPD colorimetric method was also used to measure the quantitative $\mathrm{H}_{2} \mathrm{O}_{2}$ production (at 551 $\mathrm{nm}, \varepsilon=21000 \mathrm{M}^{-1} \mathrm{~cm}^{-1}$, the detection limit in the range of $\left.0.20-0.30 \mu \mathrm{g} / \mathrm{L}\right) .{ }^{42}$ For all photocatalytic tests, multiple experiments were conducted independently.

\section{Electrochemical analysis}

Electrochemical experiments were carried out in a standard three-electrode cell system connected to a computer controlled potentiostat (Autolab, PGSTAT302N). The reactor contained a glassy carbon electrode (GCE), a platinum wire, and a $\mathrm{Ag} / \mathrm{AgCl} / \mathrm{KCl}$ (sat) electrode as a working, counter, and reference electrode, respectively, with an aqueous solution of $0.1 \mathrm{M} \mathrm{KOH}(\mathrm{pH}=13)$ as an electrolyte. Catalyst inks were prepared by dispersing a catalyst in $107 \mu \mathrm{L}$ of DI water and $93 \mu \mathrm{L}$ of ethanol followed by sonication process for $15 \mathrm{~min}$. The $75 \mu \mathrm{L}$ of as-prepared catalyst ink (421.5 $\mathrm{mg} \mathrm{L}^{-1}$ ) was drop-casted on a rotating ring-disk electrode (RRDE, glassy carbon disk and Pt ring, AG), and dried at room temperature overnight. For good adhesion of catalyst on the electrode surface, $5 \mu \mathrm{L}$ of 5 wt.\% Nafion solution (Sigma-Aldrich) and $2.5 \mu \mathrm{L}$ of a solution containing $1.2 \mathrm{~mL}$ of 5 wt.\% Nafion solution and $10 \mathrm{~mL}$ of acetonitrile (Sigma-Aldrich) were covered successively and dried at $70{ }^{\circ} \mathrm{C}$ for $6 \mathrm{~h}$. The loading density of catalyst on the electrode was about 161 $\mu \mathrm{g} \cdot \mathrm{cm}^{-2}$. Cyclic voltammetry $(\mathrm{CV})$ was performed at $10 \mathrm{mV} \mathrm{s}^{-1}$ with a potential range between $-1.2 \mathrm{~V}$ and $0.0 \mathrm{~V}$ ( $\mathrm{vs}$. Ag/AgCl), with a GCE having a geometric area of $7.07 \mathrm{~mm}^{2}$. The rotating disk electrode (RDE) and rotating ring disk electrode (RRDE) analyses were carried out by sweeping the disk potential from $-1.2 \mathrm{~V}$ to $0.0 \mathrm{~V} \mathrm{vs}$. $\mathrm{Ag} / \mathrm{AgCl}$ at $10 \mathrm{mV} \mathrm{s}{ }^{-1}$ with different rotation rates ranging from 400 to $2500 \mathrm{rpm}$, while holding the Pt ring at 0.5 $\mathrm{V}$ vs. $\mathrm{Ag} / \mathrm{AgCl}$ to oxidize the in situ produced $\mathrm{H}_{2} \mathrm{O}_{2}$ formed on the disc electrode (for only RRDE), in an $\mathrm{O}_{2}$-saturated electrolyte. The number of transferred electrons and $\mathrm{H}_{2} \mathrm{O}_{2}$ yields and were calculated using the following equation: 


$$
\begin{gathered}
n=4 * \frac{I_{d}}{I_{d}+\frac{l_{r}}{N}} \\
\mathrm{H}_{2} \mathrm{O}_{2}(\%)=\frac{200 \times \frac{l_{r}}{N}}{I_{d d}+\frac{l_{T}}{N}}
\end{gathered}
$$

where $I_{d}$ is the disk current, $I_{r}$ is the ring current, and $N$ is the collection efficiency (24.9\%).

\section{Computational calculation}

Spin-polarized density functional theory (DFT) calculations were performed by using Vienna Abinitio Simulation Package (VASP) code..$^{43}$ The plane wave cutoff energy of $400 \mathrm{eV}$ was adopted within the PBE parameterization of GGA exchange-correlation functional. ${ }^{44}$ All structures were fully optimized in the $1 \mathrm{x} 1 \mathrm{x} 1 \mathrm{k}$-mesh with the van der Waals correction by Grimme's D3 method ${ }^{45}$ until all the atomic forces are less than $0.01 \mathrm{eV} / \AA$. For the nitrogenated and oxygenated edge carbons, the graphene nanoribbon model was adopted with $20 \AA$ and $15 \AA$ vacuum regions along the transverse and vertical directions, respectively. For Gibbs free energy calculations, we used $\Delta \mathrm{G}=\Delta E^{D F T}+\Delta Z P E-T \Delta S+\Delta G_{U}+\Delta G_{p H}$ equation. ${ }^{46,47} \Delta E^{D F T}$ refers to the adsorption energy difference between intermediates by DFT. $\triangle \mathrm{ZPE}$ and $\mathrm{T} \Delta \mathrm{S}$, the zero-point energy and vibrational entropy, were calculated by using vibrational frequencies of intermediate $\left({ }^{*} \mathrm{OOH}\right)$, where we assumed $\mathrm{T}=298.15 \mathrm{~K} . \Delta G_{U}=-\mathrm{eU}$ denotes the correction by applied electrode potential, and $\Delta G_{p H}=-k_{B} T \ln \left[H^{+}\right]$the correction by solution's $\mathrm{pH}$.

\section{References}

1. Ciriminna, R., Albanese, L., Meneguzzo, F. \& Pagliaro, M. Hydrogen peroxide: A key chemical for today's sustainable development. ChemSusChem 9, 3374-3381 (2016).

2. Yamada, Y., Yoneda, M. \& Fukuzumi, S. High and robust performance of $\mathrm{H}_{2} \mathrm{O}_{2}$ fuel cells in the presence of scandium ion. Energy Environ. Sci. 8, 1698-1701 (2015).

3. Hancu, D., Green, H. \& Beckman, E. J. $\mathrm{H}_{2} \mathrm{O}_{2}$ in $\mathrm{CO}_{2} / \mathrm{H}_{2} \mathrm{O}$ biphasic systems: green synthesis and epoxidation reactions. Ind. Eng. Chem. Res. 41, 4466-4474 (2002).

4. Kim, H.-i., Kwon, O. S., Kim, S., Choi, W. \& Kim, J. H. Harnessing low energy photons (635 nm) for the production of $\mathrm{H}_{2} \mathrm{O}_{2}$ using upconversion nanohybrid photocatalysts. Energy Environ. Sci. 9, 10631073 (2016). 
5. Burek, B. O., Bahnemann, D. W. \& Bloh, J. Z. Modeling and optimization of the photocatalytic reduction of molecular oxygen to hydrogen peroxide over titanium dioxide. ACS Catal. 9, 25-37 (2019).

6. Liu, J. et al. Metal-free efficient photocatalyst for stable visible water splitting via a two-electron pathway. Science 347, 970-974 (2015).

7. Dai, L., Xue, Y., Qu, L., Choi, H.-J. \& Baek, J.-B. Metal-free catalysts for oxygen reduction reaction. Chem. Rev. 115, 4823-4892 (2015).

8. Shiraishi, Y. et al. Highly selective production of hydrogen peroxide on graphitic carbon nitride (g$\mathrm{C}_{3} \mathrm{~N}_{4}$ ) photocatalyst activated by visible light. ACS Catal. 4, 774-780 (2014).

9. Haider, Z., Cho, H. I., Moon, G. H. \& Kim, H. I. Minireview: Selective production of hydrogen peroxide as a clean oxidant over structurally tailored carbon nitride photocatalysts. Catal. Taday 335, 55-64 (2019).

10. Shiraishi, Y. et al. Sunlight-driven hydrogen peroxide production from water and molecular oxygen by metal-free photocatalysts. Angew. Chem., Int. Ed. 53, 13454-13459 (2014).

11. Zhao, S., Zhao, X., Zhang, H., Li, J. \& Zhu, Y. F. Covalent combination of polyoxometalate and graphitic carbon nitride for light-driven hydrogen peroxide production. Nano Energy 35, 405-414 (2017).

12. Zheng, Y. et al. Black phosphorus and polymeric carbon nitride heterostructure for photoinduced molecular oxygen activation. Adv. Func. Mater. 28, 1705407 (2018).

13. Peng, Y. L. et al. Visible-light-driven photocatalytic $\mathrm{H}_{2} \mathrm{O}_{2}$ production on $\mathrm{g}-\mathrm{C}_{3} \mathrm{~N}_{4}$ loaded with CoP as a noble metal free cocatalyst. Eur. J. Inorg. Chem., 4797-4802 (2017).

14. Zhao, S. et al. Carbon nanotubes covalent combined with graphitic carbon nitride for photocatalytic hydrogen peroxide production under visible light. Appl. Catal. B-Environ. 224, 725-732 (2018).

15. Kofuji, Y. et al. Hydrogen peroxide production on a carbon nitride-boron nitride-reduced graphene oxide hybrid photocatalyst under visible light. ChemCatChem 10, 2070-2077 (2018).

16. Kim, H.-i., Choi, Y., Hu, S., Choi, W. \& Kim, J. H. Photocatalytic hydrogen peroxide production by anthraquinone-augmented polymeric carbon nitride. Appl. Catal. B-Environ. 229, 121-129 (2018).

17. Baker, S. N. \& Baker, G. A. Luminescent carbon nanodots: Emergent nanolights. Angew. Chem., Int. Ed. 49, 6726-6744 (2010).

18. Yuan, F. L. et al. Shining carbon dots: Synthesis and biomedical and optoelectronic applications. Nano Today 11, 565-586 (2016).

19. Choi, Y., Choi, Y., Kwon, O. H. \& Kim, B. S. Carbon dots: Bottom-up syntheses, properties, and lightharvesting applications. Chem. Asian J. 13, 586-598 (2018).

20. Choi, H. et al. Versatile surface plasmon resonance of carbon-dot-supported silver nanoparticles in polymer optoelectronic devices. Nat. Photonics 7, 732-738 (2013).

21. El Jamal, M. M., Mousaoui, A. M., Naoufal, D. M., Tabbara, M. A. \& El Zant, A. A. Effect of operating parameters on electrochemical degradation of alizarin red S on Pt and BDD electrodes. Port. 
Electrochim. Acta. 32, 233-242 (2014).

22. Kim, T. et al. Hydrothermal synthesis of composition- and morphology-tunable polyimide-based microparticles. ACS Macro Lett. 7, 1480-1485 (2018).

23. Nwahara, N., Nkhahle, R., Ngoy, B. P., Mack, J. \& Nyokong, T. Synthesis and photophysical properties of BODIPY-decorated graphene quantum dot-phthalocyanine conjugates. New J. Chem. 42, 60516061 (2018).

24. Hu, Q. et al. Better understanding of carbon nanoparticles via high-performance liquid chromatography-fluorescence detection and mass spectrometry. Electrophoresis 35, 2454-2462 (2014).

25. Stams, A. J. M., Huisman, J., Encina, P. A. G. \& Muyzer, G. Citric acid wastewater as electron donor for biological sulfate reduction. Appl. Microbiol. Biotechnol. 83, 957-963 (2009).

26. Hoffman, A. J., Carraway, E. R. \& Hoffmann, M. R. Photocatalytic production of $\mathrm{H}_{2} \mathrm{O}_{2}$ and organic peroxides on quantum-sized semiconductor colloids. Environ. Sci. Technol. 28, 776-785 (1994).

27. Li, S. N. et al. Effective photocatalytic $\mathrm{H}_{2} \mathrm{O}_{2}$ production under visible light irradiation at g- $\mathrm{C}_{3} \mathrm{~N}_{4}$ modulated by carbon vacancies. Appl. Catal. B-Environ. 190, 26-35 (2016).

28. Kim, H., Gim, S., Jeon, T. H., Kim, H. \& Choi, W. Distorted carbon nitride structure with substituted benzene moieties for enhanced visible light photocatalytic activities. ACS Appl. Mater. Interfaces $\mathbf{9}$, 40360-40368 (2017).

29. Shiraishi, Y. et al. Effects of surface defects on photocatalytic $\mathrm{H}_{2} \mathrm{O}_{2}$ production by mesoporous graphitic carbon nitride under visible light irradiation. ACS Catal. 5, 3058-3066 (2015).

30. Shi, L. et al. Photoassisted construction of holey defective g- $\mathrm{C}_{3} \mathrm{~N}_{4}$ photocatalysts for efficient visiblelight-driven $\mathrm{H}_{2} \mathrm{O}_{2}$ production. Small 14, 1703142 (2018).

31. Moore, J. N., Phillips, D., Nakashima, N. \& Yoshihara, K. Photochemistry of "9,10-anthraquinone-2,6disulfonate. J. Chem. Soc. Faraday Trans. 82, 745-761 (1986).

32. Qiang, Z. M., Chang, J. H. \& Huang, C. P. Electrochemical generation of hydrogen peroxide from dissolved oxygen in acidic solutions. Water Res. 36, 85-94 (2002).

33. Goldstein, S., Aschengrau, D., Diamant, Y. \& Rabani, J. Photolysis of aqueous $\mathrm{H}_{2} \mathrm{O}_{2}$ : Quantum yield and applications for polychromatic UV actinometry in photoreactors. Environ. Sci. Technol. 41, 74867490 (2007).

34. Huskinson, B. et al. A metal-free organic-inorganic aqueous flow battery. Nature 505, 195-198 (2014).

35. Pham-Truong, T. N., Petenzi, T., Ranjan, C., Randriamahazaka, H. \& Ghilane, J. Microwave assisted synthesis of carbon dots in ionic liquid as metal free catalyst for highly selective production of hydrogen peroxide. Carbon 130, 544-552 (2018).

36. Wang, L. et al. Common origin of green luminescence in carbon nanodots and graphene quantum dots. ACS Nano 8, 2541-2547 (2014).

37. Song, Y. B. et al. Investigation from chemical structure to photoluminescent mechanism: a type of carbon dots from the pyrolysis of citric acid and an amine. J. Mater. Chem. C 3, 5976-5984 (2015). 
38. Choi, Y. et al. Integrative approach toward uncovering the origin of photoluminescence in dual heteroatom-doped carbon nanodots. Chem. Mater. 28, 6840-6847 (2016).

39. Liu, M. L., Chen, B. B., Li, C. M. \& Huang, C. Z. Carbon dots: synthesis, formation mechanism, fluorescence origin and sensing applications. Green Chem. 21, 449-471 (2019).

40. Choi, Y. et al. Interface-controlled synthesis of heterodimeric silver-carbon nanoparticles derived from polysaccharides. ACS Nano 8, 11377-11385 (2014).

41. Han, G. et al. Building and identifying highly active oxygenated groups in carbon materials for oxygen reduction to $\mathrm{H}_{2} \mathrm{O}_{2}$. Nat. Commun. 11, 2209 (2020).

42. Bader, H., Sturzenegger, V. \& Hoigné, J. Photometric method for the determination of low concentrations of hydrogen peroxide by the peroxidase catalyzed oxidation of N,N-diethyl-pphenylenediamine (DPD). Water Res. 22, 1109-1115 (1988)

43. Kresse, G. \& Furthmuller, J. Efficiency of ab-initio total energy calculations for metals and semiconductors using a plane-wave basis set. Comput. Mater. Sci. 6, 15-50 (1996).

44. Perduew, J.P., Burke, K. \& Enzerhof, M. Generalized gradient approximation made simple. Phys. Rev. Lett. 77, 3865 (1996).

45. Bučko, T., Lebègue, S., Hafner, J. \& Ángyán, J. G. Tkatchenko-Scheffler van der Waals correction method with and without self-consistent screening applied to solids. Phys. Rev. B 87, 064110 (2013).

46. Norskov, J. K. et al. Origin of the overpotential for oxygen reduction at a fuel-cell cathode. J.Phys. Chem. B 108, 17886 (2004).

47. Man, I. C. et al. Universality in oxygen evolution electrocatalysis on oxide surfaces. ChemCatChem 3, 1159 (2011).

\section{Declarations}

\section{Acknowledgments}

This work was supported by the National Research Foundation of Korea (NRF-2018R1A4A1022194, NRF2017R1A2B3012148, and NRF-2017M3A7B4052802) by the Ecological Imitation-based Environmental Pollution Management Technology Development Project (2019002790008) funded by the Korea Ministry of Environment (MOE), and by ICONS (Institute of Convergence Science), Yonsei University.

\section{Author contributions}

M.G and D.-Y.L contributed equally to experimental work and conducted data analysis. D.K. assisted with the synthesis of CDs. J.M. and G. L. conducted DFT calculation. H.-i.C assisted the electrochemical analysis. B.-S.K and H.-i.K coordinated and supervised the overall project. M.G., D.-Y.L, B.-S.K., and H.-i.K cowrote the manuscript. All authors discussed the results and participated in manuscript preparation. 


\section{Competing interests}

The authors declare no competing interests.

\section{Additional information}

Supplementary information in available for this paper at https://doi.org/.

Correspondence and requests for materials should be addressed to B.-S.K. or H.-i.K.

\section{Figures}

a

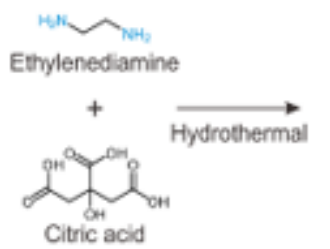

b

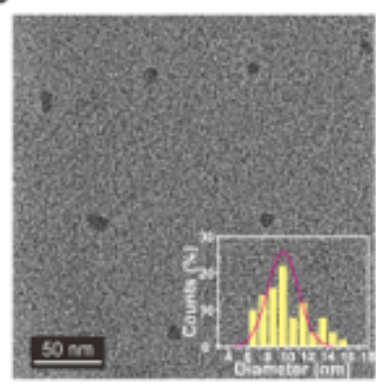

c

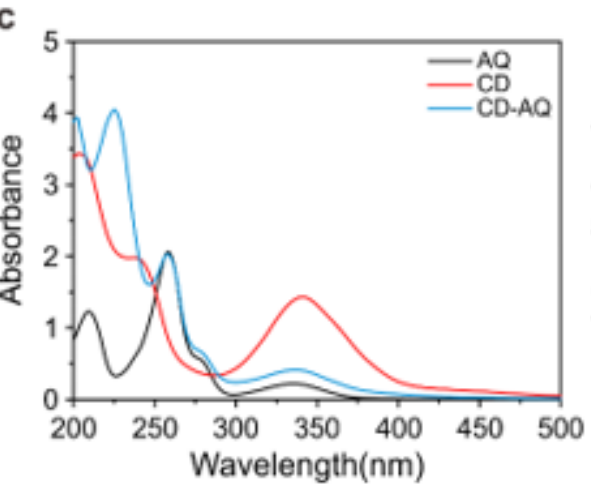

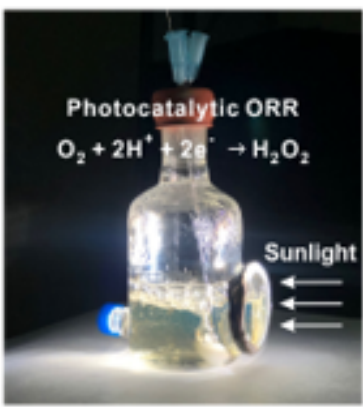

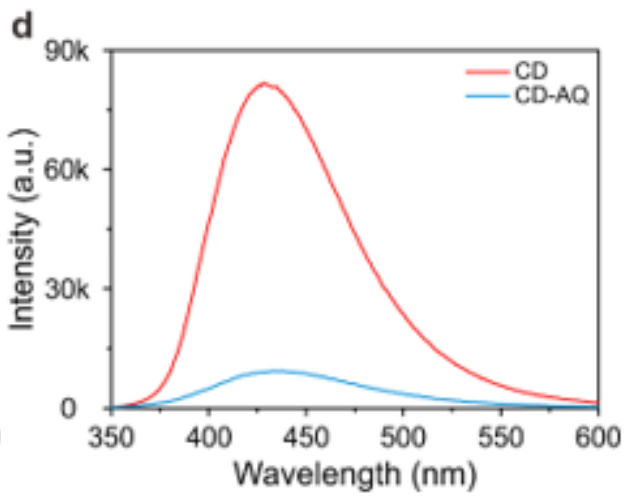

\section{Figure 1}

Characteriazation of photocatalytic CD-AQ. a Schematics of photocatalytic $\mathrm{H} 2 \mathrm{O} 2$ production using CDAQ. b TEM image of CD-AQ with a corresponding size distribution histogram. c UV/vis spectra of $A Q, C D$, and CD-AQ at a concentration of $0.12 \mathrm{mg} \mathrm{mL-1}$. d Photoluminescence spectra of CD and CD-AQ under excitation wavelength at $335 \mathrm{~nm}$, where the maximum emission of $\mathrm{CD}$ is located. 

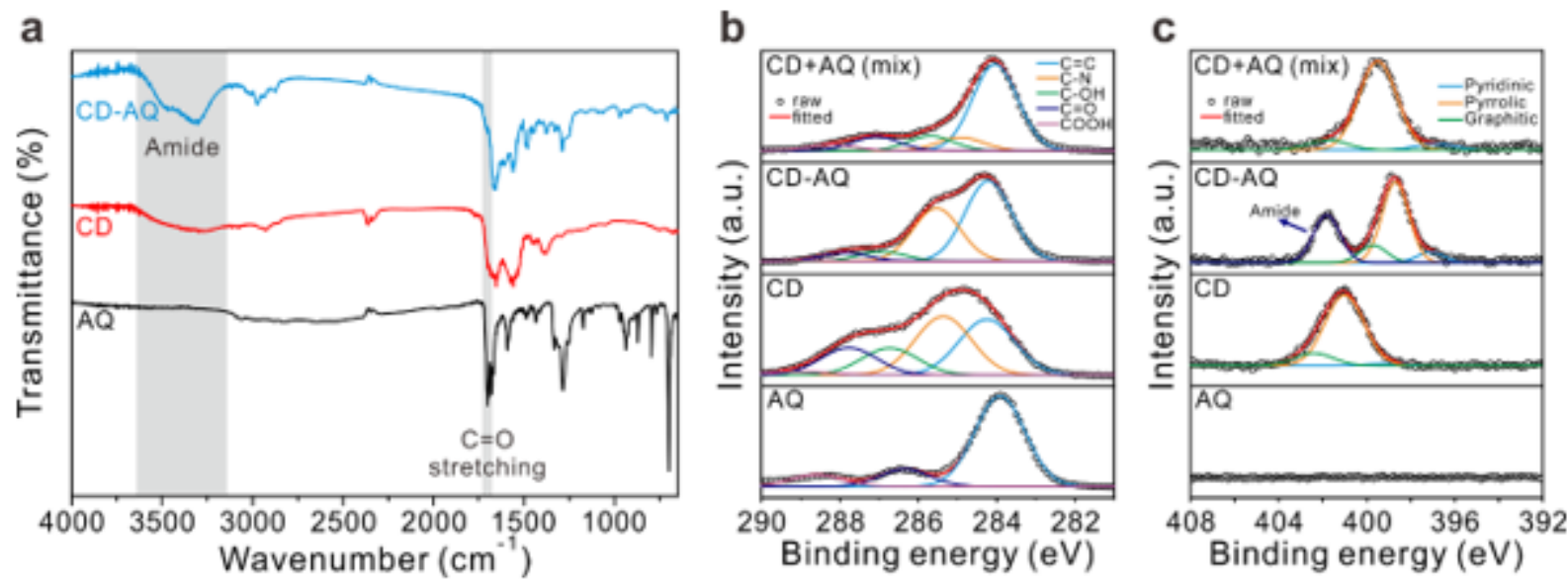

Figure 2

Chemical structures of CD-AQ. a FT-IR spectra of AQ, CD, and CD-AQ. Deconvoluted high-resolution XPS spectra of $b \mathrm{C} 1 \mathrm{~s}$ and $\mathrm{c} N 1 \mathrm{~s}$ for $A Q, C D, C D-A Q$, and a mixture of $C D$ and $A Q$.
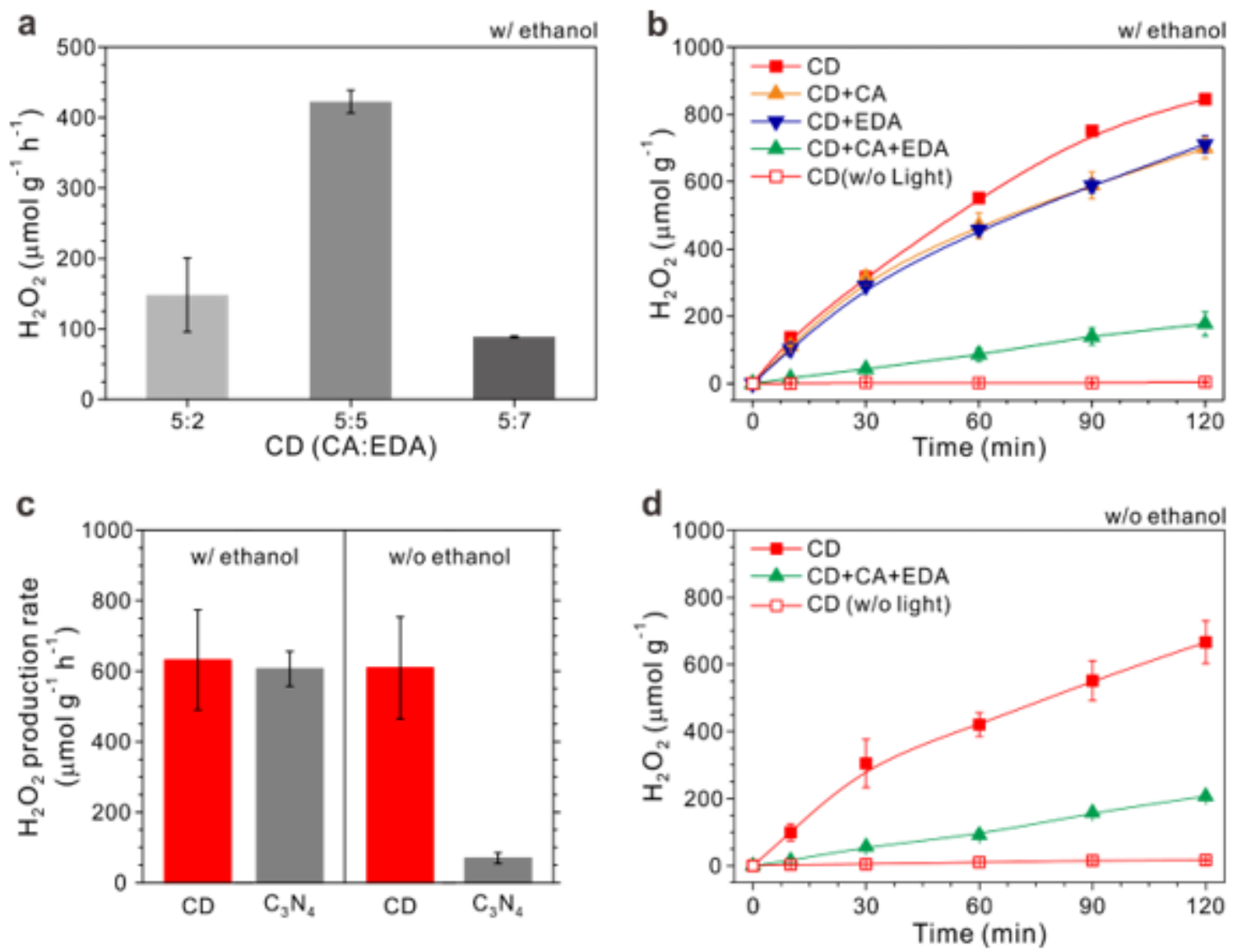

\section{Figure 3}

Photocatalytic performance of CDs. a Photocatalytic $\mathrm{H} 2 \mathrm{O} 2$ production rates of various $\mathrm{CDs}$ prepared under different ratios of CA and EDA. b Time-dependent profiles of $\mathrm{H} 2 \mathrm{O} 2$ production with ethanol by CD, 
$\mathrm{CD}$ with precursor $\mathrm{CA}$ and/or EDA, and CD without the light irradiation. c Comparison of initial $\mathrm{H} 2 \mathrm{O} 2$ production rate by $\mathrm{CD}$ and $\mathrm{C} 3 \mathrm{~N} 4$ with or without ethanol for 30 min. d Time-dependent profiles of $\mathrm{H} 2 \mathrm{O} 2$ production without ethanol by $C D, C D$ with both $C A$ and EDA, and CD without light irradiation. The experimental conditions were as follows: [catalyst] $=0.176 \mathrm{~g} \mathrm{~L}-1, \mathrm{pHi}=6,100 \mathrm{~mW} \mathrm{~cm}-2$ (AM 1.5), [EtOH]0 $=10 \mathrm{vol} \%$ (as an electron donor), and 02-saturated.
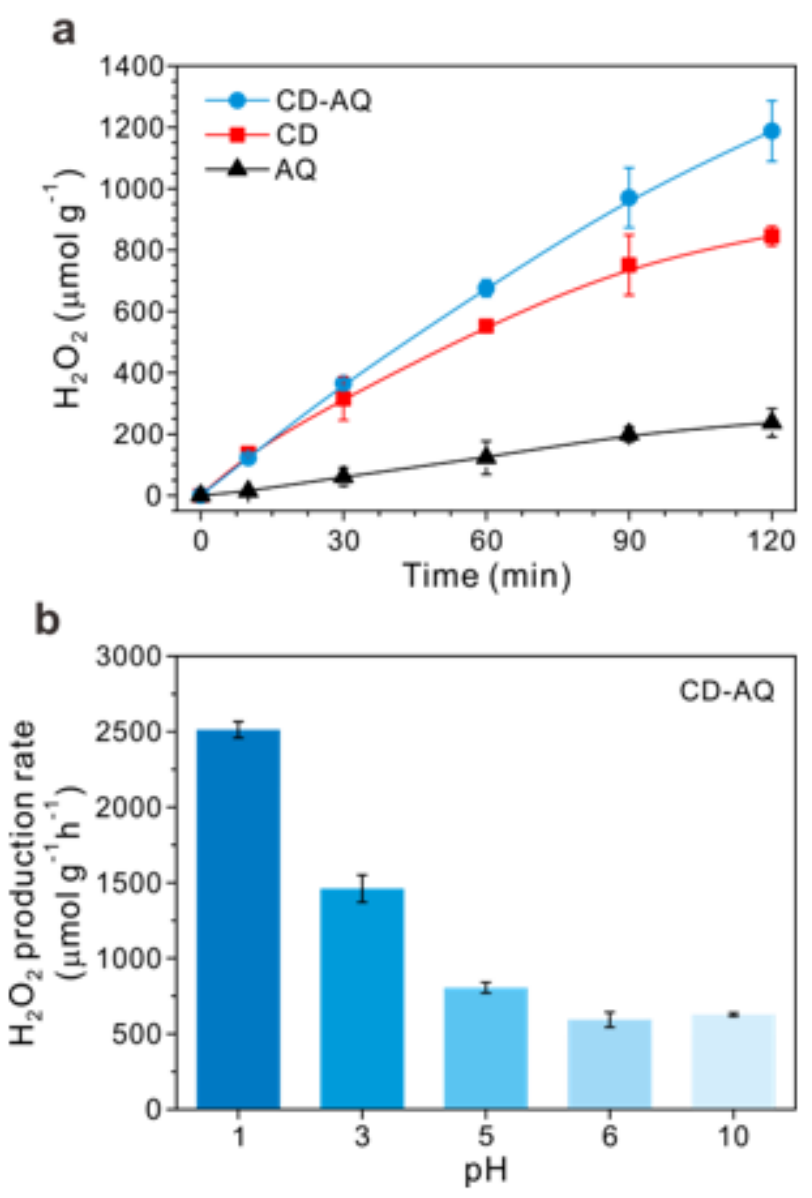

\section{Figure 4}

Photocatalytic performance of CD-AQ. a Time-dependent profiles of $\mathrm{H} 2 \mathrm{O} 2$ production by $\mathrm{CD}, \mathrm{AQ}$, and CDAQ. b pH-dependent $\mathrm{H} 2 \mathrm{O} 2$ production rate of $\mathrm{CD}-\mathrm{AQ}$ for $2 \mathrm{~h}$. The experimental conditions were as follows: [catalyst] $=0.176 \mathrm{~g} \mathrm{~L}-1, \mathrm{pHi}=6$ (for a), $100 \mathrm{~mW} \mathrm{cm-2} \mathrm{(AM} \mathrm{1.5),} \mathrm{[EtOH]0} \mathrm{=} 10$ vol\% (as an electron donor), and 02-saturated. 

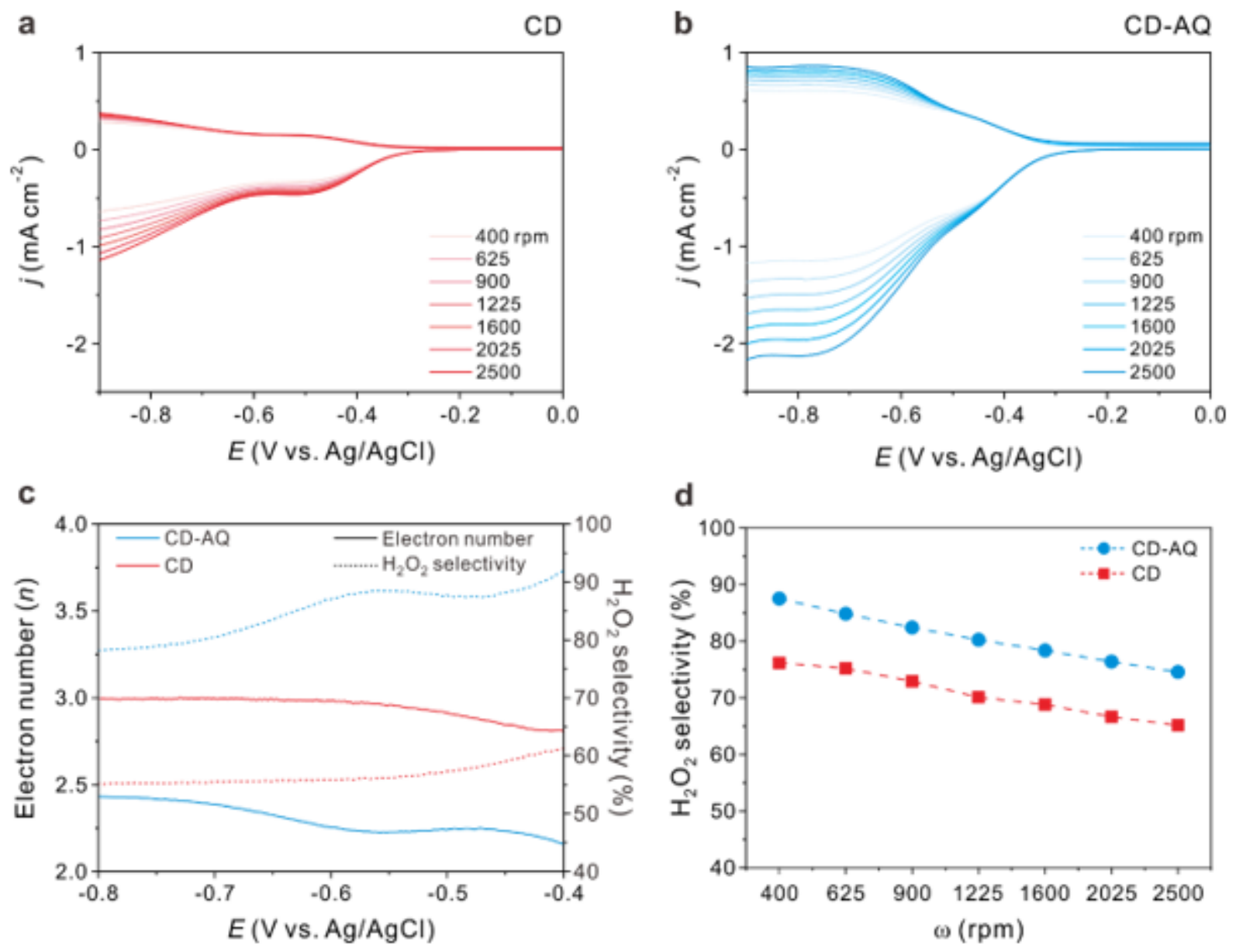

\section{Figure 5}

Electrochemical ORR performance of CD and CD-AQ. a, b ORR polarization curves in 02-saturated $0.1 \mathrm{M}$ $\mathrm{KOH}$ solution using a rotating ring disk electrode (RRDE) of $a \mathrm{CD}$ and $\mathrm{b} C D-A Q$ at various rotation speeds from $400 \mathrm{rpm}$ to $2500 \mathrm{rpm}$. c Variation of the electron number and the $\mathrm{H} 2 \mathrm{O} 2$ selectivity at $1600 \mathrm{rpm}$ as a function of the applied potential for CD and CD-AQ. d H2O2 selectivity on CD and CD-AQ at -0.55 $\mathrm{VAg} / \mathrm{AgCl}$ and $-0.80 \mathrm{VAg} / \mathrm{AgCl}$, respectively, at various rotation speeds from $400 \mathrm{rpm}$ to $2500 \mathrm{rpm}$. All measurements were performed in an 02-saturated $0.10 \mathrm{M} \mathrm{KOH}$ solution at a scan rate of $10 \mathrm{mV} \mathrm{s}-1$. 
a

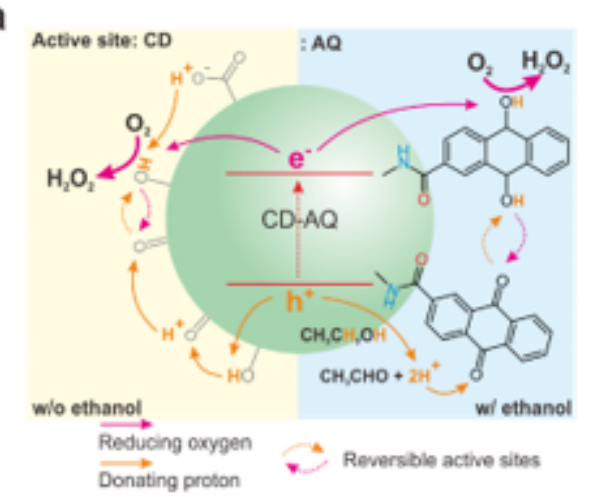

C

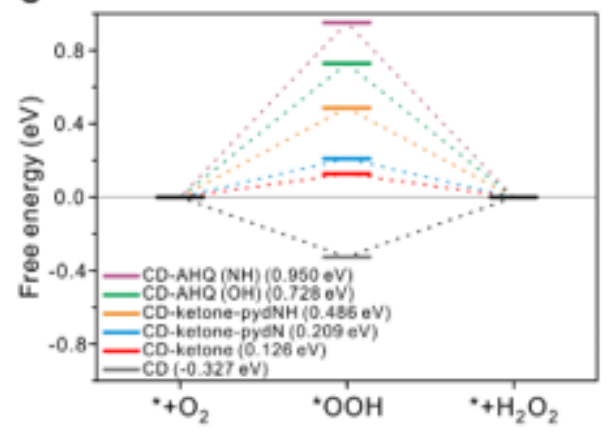

e

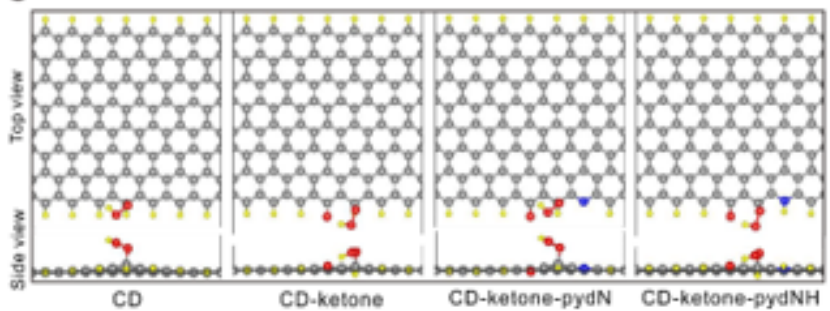

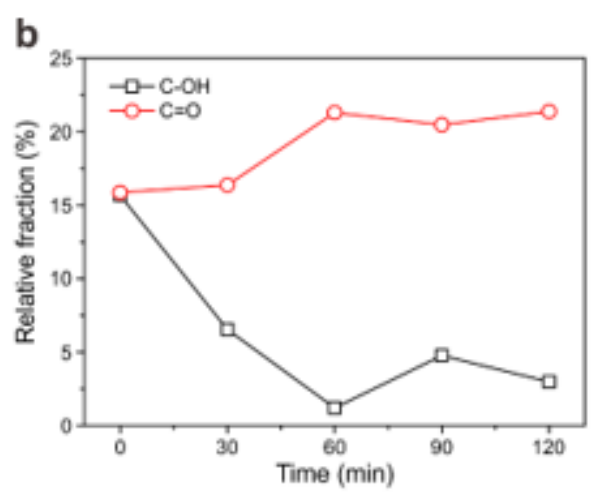

d

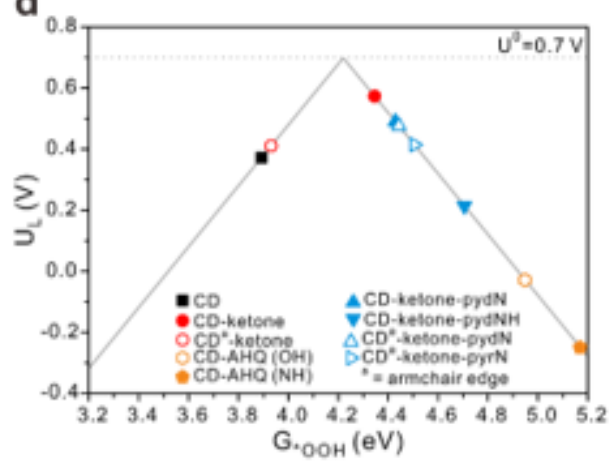

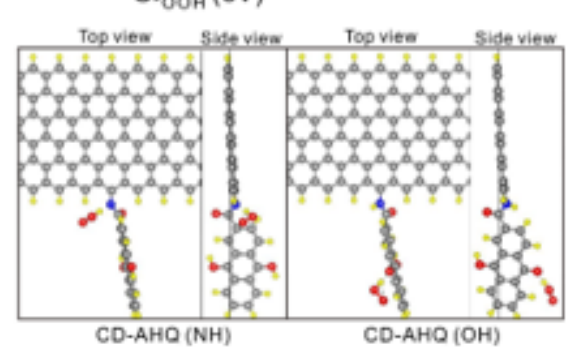

Figure 6

The dual role of surface functional groups of CD-AQ. a Proposed mechanism for photocatalytic $\mathrm{H} 2 \mathrm{O} 2$ production on the surface of CD and CDs functionalized with anthraquinone (CD-AQ) in both the absence and presence of ethanol. $\mathrm{b}$ The change in the relative fraction of $\mathrm{C}-\mathrm{OH}$ and $\mathrm{C}=\mathrm{O}$ groups on $\mathrm{CDs}$ as a function of irradiation time based on the deconvoluted high-resolution C 1s XPS spectra. c Free-energy diagram for two-electron ORR and d theoretical two-electron ORR activity volcano plot of modeling CD, CD-ketone, CD-ketone-pyridinic-N (pydN), CD-ketone-pydNH, CD-AHQ (NH), and CD-AHQ (OH). Horizontal dashed line corresponds to the thermodynamic equilibrium potential ( $\mathrm{U} 0=0.70 \mathrm{~V})$. e Corresponding atomic structures of the examined CD and CD-AQ models shown as carbon (gray), oxygen (red), nitrogen (blue), and hydrogen (yellow).

\section{Supplementary Files}

This is a list of supplementary files associated with this preprint. Click to download.

- RevisedSI.docx 